\title{
CARACTERIZAÇÃO DA ESTABILIDADE EM SISTEMAS TERNÁRIOS COM ÊNFASE NO COMPORTAMENTO DE BIODIESEL
}

\author{
P. M. de AZEVEDO ${ }^{1}$, E. R. A. LIMA $^{1}$ e A. R. TÔRRES ${ }^{2}$ \\ ${ }^{1}$ Universidade do Estado do Rio de Janeiro, Programa de Pós-Graduação em Engenharia \\ Química \\ ${ }^{2}$ Universidade do Estado do Rio de Janeiro, Departamento de Química e Ambiental \\ E-mail para contato: pati_m_a@yahoo.com.br
}

RESUMO - O estudo da estabilidade de sistemas contendo biodiesel destaca-se pela dificuldade de identificar misturas fora de especificação. Além disso, caracterizar a estabilidade é importante para os processos de separação e purificação do biodiesel após a reação de transesterificação. Este trabalho propõe um modelo a partir de estudos de estabilidade associados a modelos termodinâmicos de ELL (modelo NRTL). Foram estudados os sistemas MetOH/oleato de metila/água, MetOH/biodiesel/água, EtOH/oleato de etila/água e EtOH/biodiesel/água. O biodiesel utilizado foi obtido da reação de transesterificação do óleo de soja, por rota metílica, seguido de etapas de lavagem e purificação. O levantamento de dados envolveu: titulação, ensaios de estabilidade por separação gravitacional e tensiometria. Realizou-se um mapeamento das misturas que formaram emulsões, e mensurou-se a tensão interfacial e estabilidade destes sistemas. Com estas informações, mapeou-se o sentido de incremento de tensão interfacial e estabilidade dos sistemas preparados em relação à distribuição de suas composições dentro dos diagramas ternários correspondentes.

\section{INTRODUÇÃO}

Segundo Poling et al. (2001), muitos pares de espécies químicas podem não estar em equilíbrio em certas composições e consequentemente não formar uma única fase líquida. Isto ocorre com espécies cuja miscibilidade mútua é muito pequena em condições normais de temperatura e pressão. Desta forma, estes sistemas dividem-se em duas ou mais fases líquidas de composições distintas. Se estas fases estiverem em equilíbrio termodinâmico entre si, diz-se que o fenômeno é de equilíbrio líquido-líquido, ou ELL (Smith et al., 2007).

Felder e Rousseau (2005) definem e explicam o conceito de equilíbrio entre duas fases líquidas utilizando o sistema binário água e MIBC (metil isobutil cetona) como exemplo. Neste caso é possível obter uma mistura homogênea a $25^{\circ} \mathrm{C}$ em duas situações distintas: quando a concentração de água for superior a $98 \% \mathrm{~m} / \mathrm{m}$ na mistura ou quando houver mais de 97,7\% m/m de MIBC. Em qualquer outra proporção haverá separação de fases. Ao adicionar uma terceira substância a esta mistura bifásica, este novo composto se distribui de acordo com a sua 


\section{9 a 22 de outubro de 2014 \\ Florianópolis/SC}

solubilidade relativa em cada uma das fases existentes.

Em temperaturas e pressões próximas às condições ambientes, é relativamente simples obter experimentalmente as composições de duas fases líquidas coexistentes e a literatura técnica é rica em resultados experimentais de diversos sistemas binários e ternários em temperaturas próximas a $25^{\circ} \mathrm{C}$ e pressão atmosférica (Gmehling et al., 1977; Poling et al., 2001). No entanto, esses dados disponíveis referem-se, em sua grande maioria, a substâncias puras e de referência, como sistemas binários compostos por álcool e água. Daí a importância de se estudar o ELL de sistemas ternários que contenham o biodiesel, principalmente pela variedade de matérias-primas utilizadas na síntese do biocombustível.

Alguns dos trabalhos da literatura sobre ELL de sistemas ternários contendo biodiesel tratam da mistura deste com glicerol, subproduto da reação de transesterificação (Barbedo, 2010; França, 2013; Jorge, 2011; Azevedo, 2013). Neste trabalho, considera-se o equilíbrio entre biodiesel, água e álcoois. O objetivo é analisar até que ponto a adição de álcoois - metanol e etanol - aumentaria a solubilidade mútua entre biodiesel e água. Sabe-se que a presença de água no biodiesel diminui o calor de combustão do combustível, provoca corrosão e acelera o crescimento de colônias de microrganismos.

\section{METODOLOGIA}

Para estudar a estabilidade de sistemas ternários de biodiesel, foi necessário ter uma amostra de boa qualidade do biocombustível, saber quais foram as matérias-primas utilizadas e as variáveis do processo de obtenção do mesmo. A presença de substâncias incomuns, como contaminantes, pode interferir nos resultados esperados, principalmente de tensiometria. Assim, optou-se por sintetizar o biodiesel para realização dos ensaios experimentais previstos. E a fim de se manter o padrão de comparação, foram escolhidas substâncias puras como moléculas de referência para ensaios paralelos.

\subsection{Obtenção do biodiesel metílico de soja}

A primeira etapa do processo de síntese foi a transesterificação do óleo de soja (Liza). Foi utilizado um reator de vidro, com revestimento para controle e manutenção da temperatura interna, de três litros de capacidade total. O processo completo é descrito por Azevedo (2013).

Iniciou-se o processo de síntese do biodiesel com a agitação do óleo no reator, 260-280 rpm e temperatura constante de $45^{\circ} \mathrm{C}$, por vinte minutos. Posteriormente, para cada litro de óleo, adicionou-se $350 \mathrm{~mL}$ de álcool metílico (Vetec) e $15 \mathrm{~g}$ de hidróxido de potássio (Vetec). Este último atua como catalisador. Os reagentes ficaram em agitação por trinta minutos, e após aguardou-se cerca de quarenta minutos para a separação completa dos produtos desta reação. A seguir, após descarte do glicerol, seguiram três etapas para lavagem do biodiesel, todas estas por um período de agitação de dez minutos e um tempo de repouso para separação das fases de, pelo menos, noventa minutos.

A primeira lavagem foi feita com $400 \mathrm{~mL}$ de solução de ácido clorídrico (Vetec) 0,5\%v/v, para neutralizar o biodiesel que foi sintetizado com catalisador alcalino; a segunda lavagem foi 


\section{9 a 22 de outubro de 2014 \\ Florianópolis/SC}

feita com $500 \mathrm{~mL}$ de solução saturada de cloreto de potássio (Vetec; $310 \mathrm{~g} \mathrm{KCl}$ por litro de solução), para quebrar a emulsão formada entre o biodiesel e alguns resíduos ainda presentes nele e facilitar a retirada; e a terceira lavagem foi feita com $500 \mathrm{~mL}$ de água destilada, para retirar o excesso de álcool e as impurezas hidrossolúveis que ainda poderiam estar presentes no biodiesel.

No final, adicionou-se sulfato de sódio anidro (Vetec; aproximadamente $50 \mathrm{~g}$ para cada litro de biodiesel purificado) que ficou em contato com o biocombustível por certo período para absorver a umidade do biodiesel.

\subsection{Escolha dos sistemas ternários}

Dada a baixa solubilidade mútua existente entre o óleo e a água, mas a grande interação existente entre cada uma destas substâncias com álcoois de cadeia curta, foram escolhidos os sistemas ternários contendo o biodiesel, álcool e água. Assim, o metanol foi utilizado por ser o álcool participante da reação de síntese do biocombustível, e o etanol por ser produzido em grande escala comercialmente e seu potencial (futuro, como um possível contaminante) de ser adicionado em pequenas quantidades ao biodiesel.

Posteriormente, para conhecer e estabelecer relações comparativas, foram estudados também os sistemas ternários contendo ésteres de referência. Foram escolhidos o oleato de metila (Sigma Aldrich), que representa o biodiesel de soja sintetizado por rota metílica, e o oleato de etila (Sigma Aldrich) que, analogamente, representaria o biodiesel de soja etílico. Estes sistemas escolhidos são apresentados na Tabela 1.

Entenda-se por "água", a água tratada e purificada pelo sistema Mili-Q; e o "etanol" como sendo o álcool etílico 99,5\% (Vetec) - grau de pureza que apresentou a melhor relação custo/benefício segundo Kwanchareon et al. (2007).

\subsection{Obtenção das curvas de Equilíbrio Líquido-Líquido}

O procedimento experimental adotado iniciou-se com a construção das curvas de equilíbrio líquido-líquido dos sistemas estudados, para posterior escolha das composições a serem preparadas para os demais ensaios. No final, os resultados obtidos nos testes de separação gravitacional e tensiometria foram comparados com a disposição destas composições dentro dos diagramas ternários.

Azevedo (2013) descreveu o procedimento experimental para obtenção dos dados de equilíbrio necessários à construção das curvas de equilíbrio de fases do diagrama ternário. Este experimento consistiu em realizar titulações entre os três componentes do sistema, a fim de obter o diagrama ternário de equilíbrio líquido-líquido. O método descrito foi utilizado na obtenção de dados de todos os sistemas.

Utilizou-se uma célula de vidro com revestimento para manutenção da temperatura do sistema, e adiciona-se uma determinada proporção volumétrica de água e óleo, que formam duas fases distintas e límpidas. Em seguida, utilizou-se álcool como titulante até observar a mudança de duas fases para apenas uma fase final límpida - ponto de anilina. 
Os sistemas estudados, e cujas curvas binodais serão apresentadas, são combinações 1,2 e 3 apresentadas na Tabela 1. Por meio da leitura de composição no diagrama ternário de equilíbrio líquido-líquido, foram escolhidas as composições dos sistemas a serem preparados para os ensaios de separação gravitacional e de tensiometria.

Tabela 1: Sistemas ternários estudados, e respectivas frações volumétricas das misturas preparadas cujos sistemas tiveram o diagrama ternário de ELL construído

\begin{tabular}{|c|c|c|c|c|c|}
\hline \multirow[b]{2}{*}{ Sistema } & \multirow[b]{2}{*}{ Componentes } & \multicolumn{3}{|c|}{ Fração volumétrica (\%) } & \multirow[b]{2}{*}{ Localização } \\
\hline & & óleo & álcool & água & \\
\hline & Biodiesel de soja & 4 & 92 & 4 & Região de uma fase \\
\hline \multirow[t]{3}{*}{1} & Metanol & 10 & 80 & 10 & 2 fases, prox. à curva ELL \\
\hline & Água & 30 & 40 & 30 & Interior da região de 2 fases \\
\hline & Biodiesel de soja & 10 & 80 & 10 & Região de uma fase \\
\hline \multirow[t]{3}{*}{2} & Etanol & 15 & 70 & 15 & 2 fases, prox. à curva ELL \\
\hline & Água & 30 & 40 & 30 & Interior da região de 2 fases \\
\hline & Oleato de Metila & 4 & 92 & 4 & Região de uma fase \\
\hline \multirow[t]{3}{*}{3} & Metanol & 10 & 80 & 10 & 2 fases, prox. à curva ELL \\
\hline & Água & 30 & 40 & 30 & Interior da região de 2 fases \\
\hline & Oleato de Etila & 4 & 92 & 4 & Região de uma fase \\
\hline \multirow[t]{2}{*}{4} & Etanol & 10 & 80 & 10 & 2 fases, prox. à curva ELL \\
\hline & Água & 30 & 40 & 30 & Interior da região de 2 fases \\
\hline
\end{tabular}

\subsection{Ensaios de separação gravitacional}

Foram escolhidas três diferentes proporções de cada sistema apresentado na Tabela 1, baseadas nos diagramas de fase líquido-líquido, a $25^{\circ} \mathrm{C}$. Em cada caso, escolheu-se um ponto imediatamente acima da curva binodal que corresponde à região de uma fase, um segundo ponto imediatamente abaixo da curva binodal e o terceiro na região central do diagrama ternário. No caso do sistema que contém oleato de etila, os três pontos foram escolhidos com base no diagrama do oleato de metila, com adaptação do ponto imediatamente abaixo da curva binodal para garantir que este correspondesse à região de duas fases. Assim, foram preparadas as três diferentes emulsões para cada um dos sistemas apresentados anteriormente, todos em duplicadas. Estas informações estão resumidas na Tabela 1.

$\mathrm{O}$ experimento foi conduzido em temperatura ambiente $\left(25^{\circ} \mathrm{C} \pm 1^{\circ} \mathrm{C}\right)$. Para cada sistema, foram adicionadas as frações de cada um dos componentes, agitados por dez minutos (agitador mecânico de pás Fisatom 713D, velocidade média de $520 \mathrm{rpm}$ ), usando uma película de filme PVC cobrindo o bécher para diminuir a perda de álcool por evaporação durante a agitação. Posteriormente, a emulsão formada foi dividida em duas alíquotas: uma foi armazenada em tubo de ensaio e a outra foi levada para centrífuga para acelerar a separação de fases. Estas alíquotas foram utilizadas, respectivamente, nos testes de separação gravitacional e tensiometria. 


\section{9 a 22 de outubro de 2014 \\ Florianópolis/SC}

O ensaio de estabilidade consiste em avaliar a separação das fases oleosa e aquosa e relacionar as respectivas colunas de líquido formadas com a estabilidade do sistema. Então, cada amostra de emulsão foi colocada em um tubo de ensaio de vidro transparente e com tampa para que este ficasse em repouso por quinze dias, seguindo o procedimento usado por Almeida (2012). Este período de tempo foi estimado como suficiente para que pudesse ocorrer a separação de fases. Assim, decorridos os quinze dias, foram feitas as medições de volume de cada fase separada e, nos casos pertinentes, o volume da região que permaneceu emulsionada.

Com esses dados, puderam ser calculados dois índices para posteriores avaliações e comparações: o índice de óleo liberado (Taherian et al., 2006; McClements, 2007; Almeida, 2012), relacionando o volume de fase oleosa que se separa em relação ao volume de óleo total disponível na amostra, conforme Equação 1; e o teor de emulsão, para os casos em que parte do sistema permaneceu emulsionado, com presença de gotículas de ambas as fases, segundo a Equação 2. Considerar " $V_{i}$ " como sendo o volume da fase especificada no índice da variável.

$$
\begin{aligned}
& \text { estabilidade }(\%)=100-\left[\left(1-\frac{V_{\text {óleo }}}{V_{\text {max.possivel óleo }}}\right) \times 100\right] \\
& \text { teor de emulsão }=100 \times \frac{V_{\text {emulsão }}}{V_{\text {total sistema }}}
\end{aligned}
$$

\subsection{Ensaios de tensiometria}

As análises de tensão interfacial e superficial dos sistemas estudados foram realizadas em um tensiômetro de gota pendente DataPhysics OCA - 15E. Lima et al. (2013) apresentam a teoria e a metodologia de medição de tensão interfacial com este equipamento, que requer ainda informações do diâmetro da agulha (medido com micrômetro digital) e da massa específica das amostras (determinada no equipamento KEM Density/Specific Gravity Meter DA-640B) para fazer as medições. A separação de fases foi acelerada em centrífuga (NovaTecnica NT870), a $2600 \mathrm{rpm}$ por 90 minutos seguida de um repouso de aproximadamente 72 horas, utilizando-se tubos de centrífuga com tampas de rosca e vedação interna de borracha. A validação do procedimento de análise foi feita com a determinação da tensão superficial da água e do nhexadecano a $20^{\circ} \mathrm{C}$ e posterior comparação com os resultados do banco de dados do próprio aparelho. Os erros relativos percentuais foram $0,10 \%$ e $0,15 \%$, respectivamente.

\section{RESULTADOS E DISCUSSÃO}

A Figura 1 apresenta as curvas de ELL dos sistemas 1, 2 e 3 indicados na Tabela 1. Os experimentos contendo biodiesel foram conduzidos em duas temperaturas distintas para avaliar o efeito desta no perfil de equilíbrio. A curva com oleato de metila foi construída para comparação com o biodiesel.

Como se pode ver, a variação de temperatura alterou a curva de equilíbrio, pois quando aquela era mais alta $\left(45^{\circ} \mathrm{C}\right)$, a região de duas fases do diagrama era menor, havendo maior interação entre os componentes. A $25^{\circ} \mathrm{C}$, a região de duas fases sob cada uma das fases era maior, e percebeu-se também como o comportamento do sistema contendo oleato de metila e 
metanol era próximo ao do que continha biodiesel e metanol (curvas de círculos vermelhos e quadrados azuis, com sobreposição entre elas).

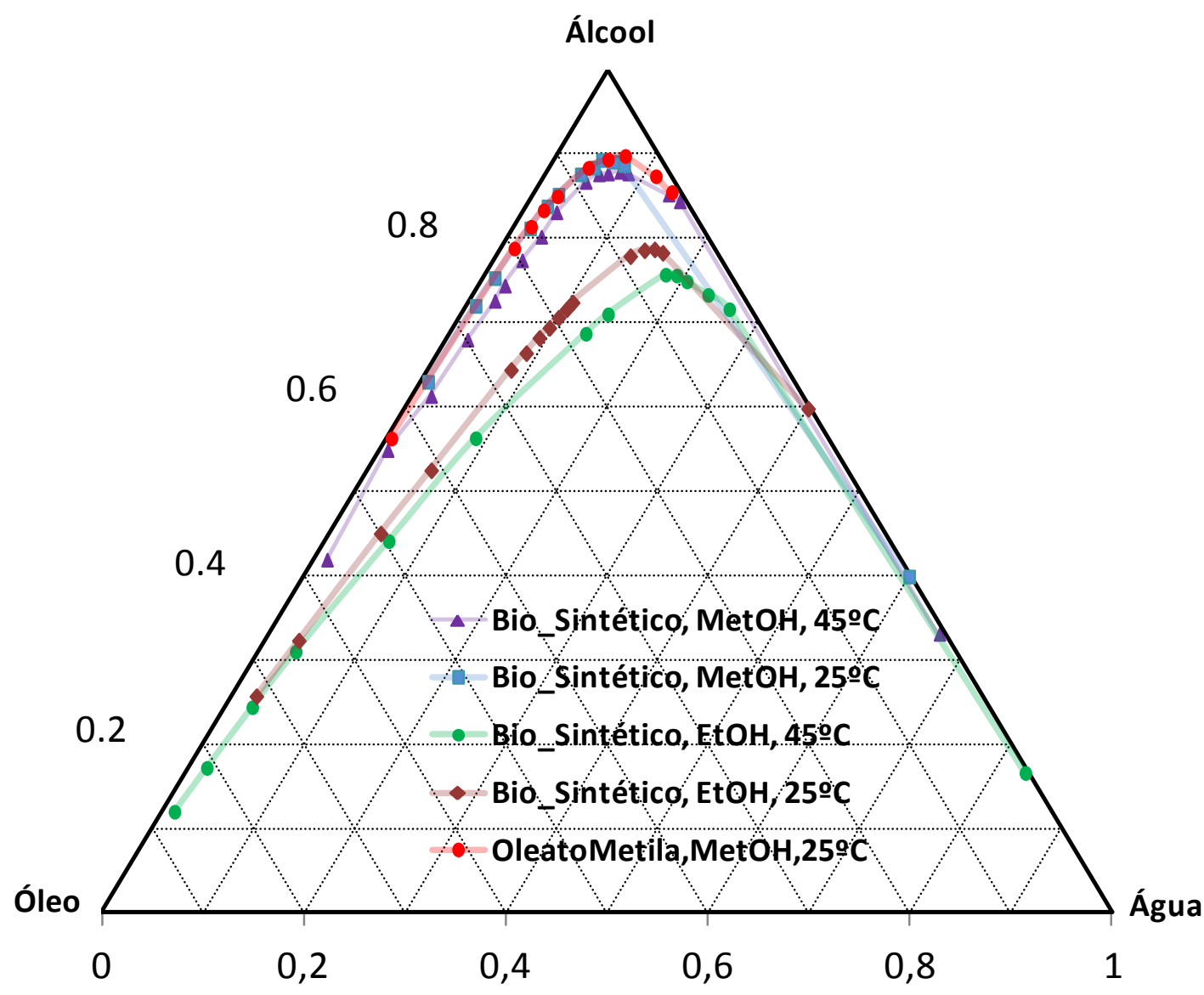

Figura 1: Curvas de ELL construídas experimentalmente.

Outra característica observada foi em relação à utilização dos diferentes álcoois, em ambas as temperaturas. Por exemplo, a $45^{\circ} \mathrm{C}$, a curva de biodiesel e metanol (losangos roxos) teve sua região de duas fases maior que a curva de biodiesel e etanol (círculos verdes). Este efeito deveuse ao aumento da cadeia do álcool que favorece maior interação entre os componentes e promove uma consequente redução na tensão na interface entre as fases (Ly e Longo, 2004).

A Tabela 2 mostra o comportamento da tensão $(\mathrm{mN} / \mathrm{m})$ de cada um dos sistemas, em cada região do diagrama ternário, de acordo com a identificação feita na Tabela 1. Observa-se como a tensão superficial (uma fase) dos conjuntos de biodiesel/metanol e oleato de metila/metanol são próximas. Entre as substâncias puras, a tensão superficial do sistema com oleato de metila/metanol (3) também foi superior a do sistema de oleato de etila/etanol (4). Em relação às tensões interfaciais, em todos os casos houve um aumento de tensão conforme as composições afastaram-se da região da curva de equilíbrio, demonstrando como a interação dos componentes na região da curva de ELL é maior do que aquelas na região interior do diagrama ternário. 
O mesmo pôde ser observado entre os sistemas semelhantes que têm como variação o álcool utilizado. Os que continham etanol apresentaram tensão interfacial menor do que os que continham metanol. Isto corrobora o comportamento observado nos diagramas da Figura 1.

Tabela 2: Tensão superficial/interfacial $\left(\mathrm{mN} \cdot \mathrm{m}^{-1}\right)$ média das composições dos sistemas estudados

\begin{tabular}{|c|c|c|c|} 
Sistemas & Uma fase & 2 fases, prox. Curva ELL & 2 fases, interior \\
\hline 1 & $23,77 \pm 0,08$ & $2,27 \pm 0,01$ & $7,08 \pm 0,02$ \\
\hline 2 & $24,11 \pm 0,04$ & $0,71 \pm 0,03$ & $4,10 \pm 0,03$ \\
\hline 3 & $23,92 \pm 0,11$ & $2,40 \pm 0,01$ & $9,22 \pm 0,04$ \\
\hline 4 & $22,90 \pm 0,03$ & $1,73 \pm 0,20$ & $4,93 \pm 0,37$ \\
\hline
\end{tabular}

Os ensaios de estabilidade tinham como finalidade determinar a capacidade de um sistema manter-se conforme sua condição inicial de equilíbrio ou não. Estes resultados estão resumidos na Tabela 3. Eles foram realizados com as misturas cuja composição estava na região de duas fases do diagrama ternário.

O sistema contendo oleato de etila e etanol foi o considerado mais estável, pois obteve a melhor separação entre as fases conforme o diagrama de equilíbrio indicava. Assim, os volumes medidos de cada fase individualmente foram os mais próximos das composições originais das misturas preparadas - em um deles houve separação total das fases. Nos outros casos, houve uma maior interação entre os componentes e a separação final das fases correspondeu a certas distorções entre os volumes medidos e as composições originais. Conforme ocorreu nos ensaios de tensiometria, os sistemas contendo etanol destacaram-se com maior índice de estabilidade que os de metanol.

Tabela 3: Estabilidade percentual média das amostras das composições de cada sistema estudado

\begin{tabular}{|c|c|c|c|c|c|c|c|c|}
\hline & \multicolumn{4}{|c|}{ Prox. à curva de ELL } & \multicolumn{4}{|c|}{ Interior diagrama ternário } \\
\hline & $\mathbf{1}$ & $\mathbf{2}$ & $\mathbf{3}$ & $\mathbf{4}$ & $\mathbf{1}$ & $\mathbf{2}$ & $\mathbf{3}$ & $\mathbf{4}$ \\
\hline Estabilidade (\%) & 63,50 & 73,40 & 66,65 & 93,85 & 72,05 & 89,25 & 98,50 & 100 \\
\hline Teor de emulsão (\%) & - & - & - & - & 18,05 & 8,05 & - & - \\
\hline
\end{tabular}

Nos sistemas com biodiesel, metanol e etanol com composição no interior do diagrama, houve a persistência de um volume de mistura emulsionada, que continha os três componentes em cada caso, pois não houve separação total das fases.

\section{CONCLUSÕES}

Conforme visto, a tensão interfacial dos sistemas estudados tem correspondência com a curva de equilíbrio líquido-líquido, pois as tensões aumentaram conforme as composições caminharam no sentido do interior do diagrama ternário. Da mesma forma, quanto mais afastada da curva de ELL é uma composição, maior é a capacidade do sistema em manter-se de acordo com as suas características originais de separação de fases (mais estáveis, segundo a definição adotada). Os resultados apresentados também mostram como o oleato de metila é uma molécula 
que pode ser utilizada para representar o biodiesel metílico de soja, uma vez que os resultados dos sistema (1) e (3) têm similaridades.

\section{REFERÊNCIAS}

ALMEIDA, T. C. A.. Avaliação da Estabilidade de emulsões concentradas em Bebidas. Dissertação (Mestrado) - COPPE/UFRJ, Rio de Janeiro. 2012.

AZEVEDO, P. M.. Estudo do equilíbrio líquido-líquido e da estabilidade de sistemas envolvendo biodiesel, álcoois e água. Dissertação (Mestrado) - UERJ, 2013.

BARBEDO, S. R.. Estudo do Equilíbrio Líquido-Líquido de Sistemas FAME/FAEE-ÁlcoolGlicerol. Dissertação (Mestrado) - Universidade de Aveiro, 2010.

FELDER, R. M.; ROUSSEAU, R. W. Princípios elementares dos processos químicos. $3^{\mathrm{a}}$ ed., LTC, 2005.

FRANÇA, B. B.. Levantamento experimental e modelagem termodinâmica do equilíbrio líquidolíquido na produção de biodiesel de soja. Tese (Doutorado) - COPPE, UFRJ, 2013.

GMEHLING, J.; ONKEN, U.; ARLT, W.. Vapor-Liquid Equilibrium Datacollection: Organic Hydroxyl Compounds: Alcohols. Dechema Chemistry Data Series, V.1, PT.2A. Frankfurt: Deutsche Gesellschaft Chemisches Apparatewesen, 1977.

JORGE, I. C. F. A.. Equilíbrio de fases do sistema ternário biodiesel de mamona-etanolglicerina utilizando a viscosidade como parâmetro para a determinação da composição das fases. Dissertação (Mestrado) - UFAL, 2011.

LIMA, E. R. A.; DE MELO, B. M.; BAPTISTA, L. T.; PAREDES, M. L. L.. Specific ion effects on the interfacial tension of water/hydrocarbon systems. Brazilian Journal of Chemical Engineering, v. 30, n.1, p. 55-62, 2013.

LY, H. V.; LONGO, M. L.. The Influence of short-chain alcohols on interfacial tension, mechanical properties, area/molecule, and permeability of fluid lipid bilayers. Biophysical Journal, v.87, p.1013-1033, 2004.

McCLEMENTS, D. J.. Critical review of techniques and methodologies for characterization of emulsion stability. Food science and nutrition, v. 47 p.611-649, 2007.

POLING, B. E.; PRAUSNITZ, J. M.; O’CONNELL, J. P.. The Properties of gases and liquids. $5^{\mathrm{a}}$ ed., McGRAW-HILL, 2001.

SMITH, J. M.; VAN NESS, H. C.; ABBOTT, M. M. Introdução à termodinâmica da engenharia química. $7^{\mathrm{a}}$ ed., LTC, 2007.

TAHERIAN, A. R.; FUSTIER, P.; RAMASWAMY, H. S.. Effect of added oil and modified starch on rheological properties, droplet size distribution, opacity and stability of beverage cloud emulsions. Journal of Food Engineering, v. 77, p. 687-696, 2006. 